\title{
Piloting career development: Whole school interventions
}

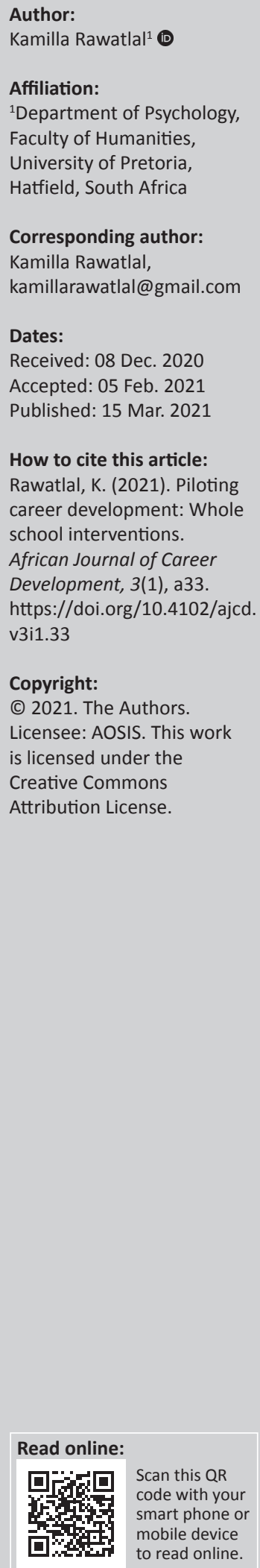

Background: The article reports on a project that was undertaken as a pilot study for a wholeschool approach (WSA) to career education intervention that was integrated into the Grade 10, Life Orientation (LO) curriculum at a public, secondary school in KwaZulu-Natal, South Africa.

Objectives: Using an ecological framework, interventions to improve learners' future orientation and motivation were piloted with Grade 10 learners' at the micro-, meso- and macro-level to inform career education.

Method: An approach, using an intervention and control school involving three phases was conducted. The mixed method evaluation involved the administration of baseline questionnaires to all Grade 10 learners and included, the Psychological Sense of School Membership (PSSM), the Future Orientation Scale (FOS). Multivariate analysis and repeated measures of analysis and variance were also conducted. Qualitatively, process evaluation using fidelity checklists and post intervention interviews, with key informants was conducted. Focus group sessions with learners were also utilised.

Results: The findings support how career learning can be integrated and evaluated in a whole- school curriculum. In a WSA, an integrated system of career education in every secondary school is proposed.

Conclusion: This research supports the call for career education to be shifted from a peripheral to a central role that can be integrated into the curriculum. This study, although in a limited way, supports the need for broader, contextual approaches to career development, and acknowledges the vital role school membership and career development play in the mental health promotion of adolescents.

Keywords: career development; ecological approach; future orientation; curriculum; intervention; process evaluation; outcome evaluation.

\section{Introduction}

A whole-school approach (WSA) focuses on shaping the whole school, and this includes the school's ethos, relationships, organisational and management structures, the physical environment, the taught curriculum, and pedagogic practice, so that the experience of school life is conducive to the health of all who learn and work there (Weare \& Markham, 2005). Wholeschool approaches are increasingly advocated for the prevention of high-risk behaviour amongst adolescents in low- and middle-income countries. Implicit in a WSA, is an integrated system of career education (Stead \& Watson, 2006). This approach to career education encourages a diversity of activities that is systematic, coordinated and transcends boundaries of academic subjects to 'enhance the career development of all students throughout the school experience' (Miller, in Peterson, Sampson, \& Reardon, 1991, p. 164). This approach to career education is based on the premise that in making the transition from school life to adulthood, all learners need guidance in exploring their interests and abilities (Avent, 1988).

Such an approach to make career education in South Africa more accessible is critical, given the work of Maree (2013; Savickas, 2012a), who identified that despite the documented importance of career counselling it is typically young people whose parents can afford it, that access the service.

Motivation has been identified as the most powerful determinant of students' achievement in school (Hardre, Crowson, \& Teresa, 2007), and research also identifies that students who are highly motivated in school are less likely to engage in high-risk behaviour. Braddock and McPartland (1993) identify that in enhancing young peoples' motivation, a curriculum that is associated to real world situations and sense of future orientation are critical factors. Adolescents' future goals and sense of future orientation is shaped not only by intrinsic 
factors (personality, skills and interests) but also by extrinsic factors such as living conditions in the family and other influencing institutional factors in his or her environment, such as the school. Alm, Låftman Brolin, Sandahlc and Modinb (2019) indicate that this however has been studied to a much lesser extent. Schools are viewed as providing engagement opportunities with adults who can serve as role models and provide guidance and support in terms of career choices. Alm et al. (2019) indicate that no study has investigated the links between the school context and student's future orientation.

In this study, the purpose was to address the need to provide comprehensive WSAs with a focus on the role of career education in enhancing the motivation of learners and strengthening experiencing a sense of school membership. The gap it sought to address was gauging the views of students, teachers and school management, as to how career education can be integrated in the current teaching and learning curriculum to increase adolescents' sense of future orientation and school membership.

\section{Literature review}

Future orientation, referring to hopes, aspirations and expectations, has been found to be related to motivation and attitude towards school and learning. It has been found to influence adolescent identity formation, goal setting and ability to make decisions (Kerpelman \& Mosher, 2004). Studies have also indicated that optimism about achieving future goals is also related to enhancing coping skills and resilience to traumatic events (Marko \& Savickas, 1998). Unfortunately, they indicate that many individuals living in a diverse society do not orient themselves to the future and seldom, if ever, think about how their careers might unfold (De Volder \& Lens, 1982; Feather \& Bond, 1983; Fitzgerald \& Betz, 1994). Individuals who do not experience significant encouragement and reinforcement for goal setting and planning appear to be less inclined to learn a future orientation (Nurmi, 1991). In light of the disparities in the delivery of basic education in South Africa, researching adolescents' future orientation and expectations is regarded as particularly relevant.

According to Goodenow (1993), school membership is regarded as the degree to which learners perceive themselves to be welcomed, valued and treated as respected members. A lack of school membership has been associated with a higher incidence of mental and physical illness. Resnick et al. (1997) reported that an adolescent's sense of belonging to family and school was significantly associated with lower rates of emotional distress, suicidality (defined as a recent history of suicidal ideation and attempts), violence, substance abuse and sexual activity. Eccles and Midgley (1989) indicated however, that ironically, as children reach adolescence, such school support declines. It is thus indicated that in promoting a sense of belonging and support, extra effort and support is needed from the school community in secondary schools. Goodenow (1993) concluded that if students believe others within the environment are supporting them, are on their side, and are willing to help them if necessary; they can also believe that they have the resources they need to be successful. Expecting to be academically successful is not only a matter of students' sense of their own individual abilities, but also a sense of access to supportive resources, and the encouragement and help they feel they can secure from others. This is seen as especially important for at-risk students.

Research on comprehensive WSAs to career education in South Africa is limited. In only one study identified, Singh (2003) revealed a lack of whole-school development in disadvantaged schools in South Africa and a pressure on teachers to develop their own intervention strategies. A recommendation of his study was the need for teachers to be trained on whole-school development to alleviate the pressure. The Department of Higher Education and Training (DHET) (2014) also recognises a lack in delivery of effective comprehensive career education in many South African schools. Career intervention research has also been found to be limited to a single, 'once off' programmes included in the school programme: for example Miles' (2015) study on the 'impact of a career development programme on the selfefficacy of Grade 11 learners', in a South African province.

\section{Conceptual framing}

The eco-systemic model focus, on the role of societal issues and the interaction of different systems and their influence on the sense of future orientation in adolescence is given consideration in this study. Bronfenbrenner's (1979) ecological model highlights the interaction between multiple levels of influencing systems. The model targets multiple levels of intervention at the different levels of influence that combine environmental and behavioural components. The intrapersonal level (micro-level) influence of individual characteristics such as motivation, goal directedness, future orientation and selfregulation is highlighted in influencing behaviour and promoting career decision-making. At the interpersonal level (meso-level) recognises the relationships with significant others, such as peers, role models in influencing future orientation and the community level (macro system) which recognises the influence of the school context (practices, structures and activities) that support the future orientation of learners and strengthen the experience of membership at the school.

In the context of promoting a sense of future orientation and membership, the macro system is of importance. Future expectations are orientations that are decisively influenced by the macro system which is informed by the economy, politics, social health, values and the nature of the community. At this level, the relative importance given to career education, (at the level of school level of policy, teaching and learning and curriculum) is highlighted to play a crucial role in learners experiencing a sense of school membership, motivation and prevention of highrisk behaviour. The objectives of the study were to firstly implement intervention to strengthen school membership and positively impact adolescents' future orientation and motivation at the micro-, meso- and macro-level. Secondly, to evaluate systematically at the various levels, using both 
an outcome (quantitative evaluation) and process (qualitative evaluation) the efficacy of the interventions piloted to improve school membership and adolescents' sense of future orientation.

\section{Research methods and design}

The design of this study involved three phases. Phases one and two, which formed the contextual background to the study included a situational analysis (phase one) and implementation of the intervention (phase two). Phase three, the focus of the manuscript involved the evaluation of the intervention and is discussed thereafter.

\section{Contextual background}

Phase one titled 'Factors impeding school connectedness', published in the South African Journal of Psychology (SAJP) (Rawatlal \& Petersen, 2012), involved a situational analysis in the intervention school (a local, public, English medium high school in KwaZulu-Natal) of factors that hinder school connectedness. Fifty-six Grade 10 learners and seven school managers comprised the sample. In terms of gender, the learners included 27 men and 29 women, between the ages 15 and 16 . The learner and teacher sample population groups comprised participants from the African, white, Indian and coloured communities. Semi-structured interviews were conducted with the teachers and managers $(n=7)$ and focus groups were conducted with the learners. In this article, however, the focus refers to the career education component and readers are invited to peruse the SAJP article for other information.

In summarising the results of the situational analysis pertaining to career education and that formed by the contextual background to the study and interventions piloted, participants indicated that they were aware of career education through the Life Orientation (LO) curriculum but that LO was too diffuse and did not really focus on useful career education.

The importance of career education integrated into the curriculum, and the critical role it plays in motivating learners at school, was thus identified. Participants (teachers and managers) indicated that learners who were motivated, and goal- and future-oriented were less likely to engage in deviant behavior and therefore experienced greater acceptance and connectivity to the school. Marko and Savickas (1998) indicate that a hallmark characteristic of human thought and action is future orientation. Modern motivation psychology highlights the importance of future orientation for psychological wellbeing (Nurmi \& Salmelo-Aro, 2002); with studies showing that personal goals are connected to one's psychological well-being (Emmons \& King; Nurmi \& Salmelo-Aro, 2002). In respect of career education intervention, the situational analysis revealed that beyond formalised career education programmes that can assist with this, teacher and the school curriculum involvement can play a critical role. Broomfield (2007), in a study of resilient youth, attributed positive outcomes in youth to having teachers who they experienced as accepting and providing guidance in creating and attaining future goals.
In phase two, implementation at the macro-level, focused on the teaching and learning curriculum; education policies and student representative bodies in promoting career education, future orientation and aspirations of learners. Intervention aimed to address the lack of a focus on careers and future orientation at the school and level of basic education, and engage the participation and collaboration of key stakeholders (learners, teachers and mangers) in informing intervention. In July 2011, the researcher conducted three two-hour workshops with the participants and engaged them in conversation with regard to integrating career education in the curriculum (LO lesson plans) and to enhance the future orientation aspirations and motivation of learners. By opening the lines of communication at this level, the desired outcome was to create greater school cohesion and a school ethos that valued promoting the future aspirations and motivations of learners. At this level, the need to address macro-contextual factors in promoting career education and sense of future orientation is highlighted. Whilst there are some scholars who are somewhat encouraged by the career development component of the LO subject (Watts, 2009) in schools, there are others who are highly critical in terms of the content material and the training of teachers (Gounden, 2009), and argue for a rethinking of how career counselling is promoted at schools (Maree, 2013; Watson, 2010). A repositioning of career education as central in addressing students' motivation at school, which is argued to be a basic human right, is highlighted at this level.

At the meso-level, the influence of peer mentoring groups is highlighted. In the context of this study, mentoring relationships were found to strengthen connectivity of adolescents to the school through providing positive role models and activities to develop a sense of future orientation. In the intervention, 15 peer mentors were trained and the programme was implemented over a year and 6 months in March 2011.

At the micro-level, the development of individual characteristics in promoting future orientation and preventing adolescents' engagement in high-risk behaviour was highlighted. Lesson plans focused on 'adopting a future oriented time perspective'. In August and September 2011, these plans were integrated into the LO lesson plans, accompanied by a workshop with the LO teachers for implementation.

In phase three, an evaluation of intervention piloted at the micro-, meso- and macro-levels is discussed.

\section{Data collection measures}

In phase three, a quantitative, outcome evaluation was conducted to explore whether the intervention enhanced learners' sense of future orientation and school membership. A quasi-experimental approach, utilising, pre- and post-test measures in the control and intervention school was administered. Quasi-experimental designs typically refer to a treated and untreated group, and they have been referred to as having greater application in the 'real world' 
(Gilbody \& Whitty, 2002). In the identification of a matched control school in the study, the school principal indicated matched features of the demographics of the teacher and learner populations, and that no previous interventions were administered at the school.

The outcome measures used to assess future orientation included two subscales: the Reason for Achievement Scale (Ibanez et al., 2004) measures academic motivation and the second subscale, the Value of Academic Success Scale by Fulgini (1997) included three measures. Both subscales were combined to inform the Future Orientation Scale (FOS). The scale comprised 17 items and the Cronbach's alpha co-efficient 0.68 , indicating acceptable internal reliability. The outcome aims to assess school membership with the Psychological Sense of School Membership (PSSM) Scale, by Goodenow (1993). This instrument included 18 items and the Cronbach's alpha co-efficient for this scale was 0.81 .

The outcome evaluation involved pre- and post-measures that were administered in both schools to Grade 10 learners. Pre-intervention surveys were administered in March 2011 and included 137 surveys completed at the intervention school, and 123 surveys completed at the control school. Post-intervention surveys were administered in November 2012 and included 137 surveys completed at the intervention school, and 123 surveys completed at the control school.

For the process evaluation component of this study, qualitative data measures were used. Methods utilised included semi-structured interviews, focus groups and analysis of documents. Document analysis included collecting samples of learners' completed activity sheets in August to September 2011. In the post process evaluation, four focus groups comprising fifteen Grade 10 learners and five semi-structured interviews were conducted with teachers and managers.

\section{Data analysis}

Data collection and analysis occurred simultaneously. In the outcome evaluation, the null hypothesis was that there would be no increase in school membership and future orientation in the intervention school. The alternate hypothesis was that there would be an increase following the intervention. Descriptive statistics, using the Statistical Programme for Social Sciences (SPSS) was utilised in the data analysis.

In the process evaluation, thematic content analysis (Richie \& Spencer, 1994) was used. The five stages to analysis included: familiarisation of the range and diversity of the material gathered, location within a theoretical framework, indexing of data in textual form, charting of attitudes and experiences collected from the transcripts and placing them into thematic categories and lastly, mapping and interpretation of the data collected.

\section{Reliability and validity}

In enhancing reliability in qualitative research, the process of generating themes, concepts and theories was documented and presented to the school to illicit feedback. Triangulation and collecting information from different sources were also utilised.

\section{Ethical considerations}

Permission to carry out this research was obtained from the Research Ethics and Higher Degrees Committees of the University of KwaZulu-Natal and the Department of Basic Education (HSS/0316/09). Informed consent was obtained from participants and code names were assigned to each of them to ensure anonymity and confidentiality. In addressing researcher bias, the researcher explored her positionality through reflexive analysis. 'Within positionality theory, it is acknowledged that people have multiple overlapping identities and that people make meaning from various aspects of their identity' (Kezar, 2002, p. 96). It was acknowledged that as much as the researcher gained in her role as a participant in the study, her identity as a Counselling Psychologist employed in higher education served to distance her from fully engaging with participants in the study. The role that this could have played in distancing the researcher as participant is acknowledged. The challenge (at initiation of the study) was identifying that there already existed power imbalances in the school structure, between teachers, managers and learners at the intervention school. The researcher had to be mindful of how her role could have served to unsettle, reinforce or transform power imbalances whilst trying to gain the schools co-operation for the programme implementation. The transformational agenda of this study, based on critical theory, located the researcher as an active participant in the study. The researcher was thus able to locate herself as a collaborator, who also served to empower her participants.

\section{Results}

In the outcome evaluation, a comparison of the baseline and post-test scores of the control and intervention schools indicated that PSSM increased from the baseline to post-test for the intervention group. Baseline to post-test increased from $M=61.41$, standard deviation (SD) $=11.90$ to $M=67.20$, $\mathrm{SD}=3.35$. This was indicative of learners' sense of school membership being enhanced following the intervention. A comparison of baseline and post-test scores of the FOS, indicated an increase of FOS scores at the baseline from $M=54.21, \mathrm{SD}=5.31$ to post-test $M=58.28, \mathrm{SD}=3.10$ for the intervention school.

In the control school, there was, however a decrease in PSSM pre-test to post-test scores with $M=55.50, \mathrm{SD}=11.46$ to $M=43.40, \mathrm{SD}=3.46$ indicated for the group. A decrease from pre-test $(M=56.91, \mathrm{SD}=5.25)$ to post-test $(M=48.24$, $\mathrm{SD}=5.61)$ on this measure for the control group was also indicated. Regarding, the FOS, there was also a decline in the control school measure scores from pre-test $(M=56.91$, 
$\mathrm{SD}=5.25)$ to post-test $(M=48.24, \mathrm{SD}=5.61)$ for the control group.

The role of the intervention in enhancing learners' future orientation and sense of school membership is highlighted. However, a decrease in PSSM and FOS in the control group was unexpected. This is attributed to history effect at the time of the intervention at the control school. Campbell and Stanley (1963) indicate that it is important to note history effects when any historical or external event may influence the study findings. In relation to this study, the researcher was alerted to the possible closure of the control school in 2012. The apathy of the participants at the control school may have thus influenced the decline in FOS and PSSM scores.

Repeated analysis of variance (ANOVA) from baseline to post-test scores indicated a significant change in learners' sense of school membership (PSSM) as shown in Table 1. This indicates a differential change across time between the intervention and control groups $(F[1258]=387.36$; $p<0.001)$.

With the FOS repeated, ANOVA from baseline to post-test showed a significant change in participants' sense of future orientation, in the intervention school compared to the control school. This was indicative of a differential change across time between the intervention and control group $(F[1258]=72.57 ; p<0.001)$ as indicated in Table 2 .

The outcome findings for the PSSM and FOS measures thus indicated an enhancement of experiencing school membership and future orientation at the intervention school. Whilst the outcomes for the control school indicated a decline in the measured scores, the validity of the findings in relation to the possible school closure and participants apathy must also be acknowledged and taken into consideration when interpreting the findings. The Outcome evaluation findings, however, support a rejection of the null hypothesis in which there would be no significant difference in the outcome measures between the two schools post intervention measures.

TABLE 1: Repeated analysis of variance for the psychological sense of schoo membership.

\begin{tabular}{lcccc}
\hline Source of variance & Mean squares & $d f$ & $\boldsymbol{F}$ & $\boldsymbol{p}^{*}$ \\
\hline PSSM & & & & \\
Intercept & 28605.40 & 1 & $387.36^{*}$ & $<0.001$ \\
Error & 73.85 & - & - & - \\
\hline
\end{tabular}

$d f$, degrees of freedom; PSSM, psychological sense of school membership.

$*, p<0.001$

TABLE 2: Repeated analysis of variance for sense of future orientation scale.

\begin{tabular}{lcccc}
\hline Source of variance & Mean squares & $d f$ & $F$ & $p^{*}$ \\
\hline FOS & & & & \\
Intercept & 1747.17 & 1 & $72.57^{*}$ & $<0.001$ \\
Error & 24.08 & - & - & - \\
\hline
\end{tabular}

$d f$, degrees of freedom; FOS, future orientation scale.

$*, p<0.001$.

\section{Process evaluation}

In exploring the processes that influenced the results in the outcome evaluation phase, the results of a descriptive process evaluation, utilising focus groups and semi-structured interviews are discussed in the following section.

\section{Intrapersonal level}

Results at this level indicated that learners viewed future orientation as important in their individual development. The effectiveness of the 'Goal Setting Ladder' was highlighted by all the learners. This was indicated through the following excerpts:

'It helps me to see where I am today and what I need to do in the future to get there.' (Participant learner, nos. 6, August 2011)

Learners indicated that the activity supported them in identifying challenges and obstacles they may experience in arriving at their goals and how to overcome them:

'It helped me to see what obstacles there maybe like, finances and living away from home. It helps me see the "bigger" picture.'

(Participant learner, nos. 12, August 2011)

Documenting (writing) out their long-term and short-term goals in this activity enabled greater self-monitoring. Reflection of goals was also encouraged as a means to 'challenge seeking', and learners were able to acquire skills to navigate failure and become resilient:

\section{GOAL SETTING \\ Goals are specific objectives that help us to plan our activities and strategies. \\ A short term goal is a goal that only takes a few days or weeks to achieve e.g. daily homework tasks. \\ A long term goal takes several weeks, months, or even a full school semester e.g. to improve a grade in a certain subject. \\ Goal Setting Questions \\ 1. What is the one area of my school performance I want to improve? \\ Ny academics $\rightarrow$ my Physics, Maths, EGD \\ 2. What is the one thing I can do to accomplish my long term goal ? \\ Set small goals which lead to big hings \\ 3. How can this short term goal be broken down into a step-by step plan? \\ Do well in tests, assignments, focus on this Ist \\ I should focus and Keep to my hime-rable \\ 4. What are the things that might get in my way as I work toward my goal ? Obstacles, Time Management, Insufficient Funds. \\ 5. How will I remind myself of my goal?$$
\text { Visualise st all the time. Think of the ladder (1) }
$$

Source: Rawatlal, K.V. (2014). The development, implementation and evaluation of interventions to build school connectedness: A pilot study. Unpublished doctoral dissertation. South Africa: University of KwaZulu-Natal

FIGURE 1: Learner's response to the goal setting ladder. 


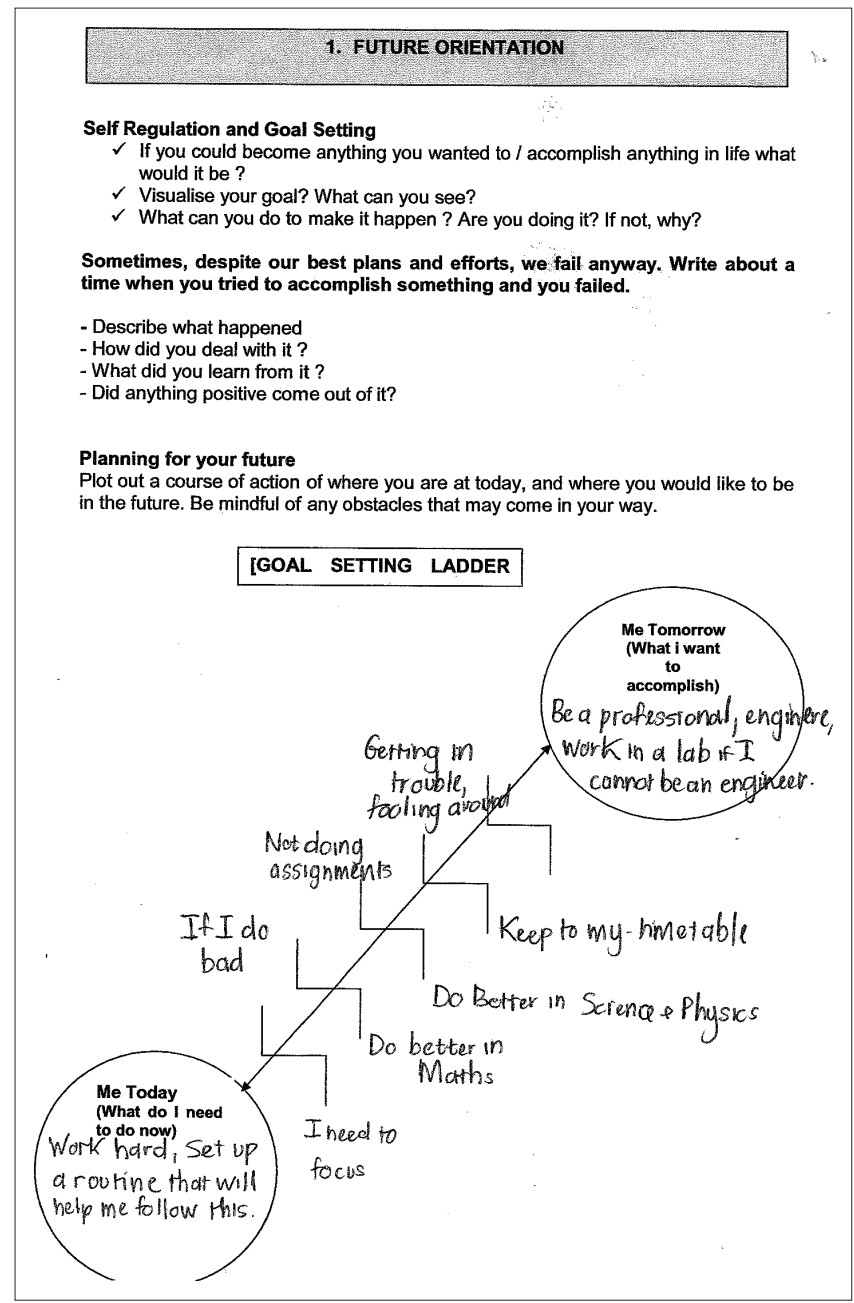

Source: Rawatlal, K.V. (2014). The development, implementation and evaluation of interventions to build school connectedness: A pilot study. Unpublished doctoral dissertation. South Africa: University of KwaZulu-Natal

FIGURE 2: Excerpt of learner applying himself to the future orientation and goalsetting activity.

' $[I]$ t helps me to write it, in the Goal setting ladder. I can see that I have bad marks in Physics and I need to improve to become a doctor. I must now try harder and do better not only in Physics but with all my subjects.' (Participant learner, nos. 8, September 2011)

A sample of a learner's response to the activity is indicated in Figure 1. A sample of a response to the Goal Setting Ladder is indicated in Figure 2.

Teachers also indicated the importance of 'future orientation' in career education. They however viewed that they would need further training and support in developing activities as career education implied 'process work' and engaging students in constant self-assessment, goal setting and reviewing of goals, leading to choosing a career path:

'Future orientation is a useful way of getting them to assess themselves and become realistic about their potential. I don't believe however that all teachers will have this ability to get them thinking in this "cyclical" or "process" oriented way ... they need specialized training for this. It is important because many learners think that careers is a "once off" action that just involves filling out some forms!' (Participant teacher, nos. 2, August 2012)
At the interpersonal level, learners indicated how forming of groups such as the peer support programme enhanced collaboration and led to experiencing greater membership at the school. The mentors were referred to as members of the school who could serve as role models and encourage learners' participation in career education and development activities. Some of the activities the peer mentors initiated included career presentations for Grade 9 learners focusing on subject choices, academic support groups, where mentors tutored students:

'The peer mentor support programme is helping me learn more about my career. We are all finding out about different career paths and sharing in out groups through the programme.' (Participant learner, nos. 4, August 2011)

At the school community level, the researcher attempted to shift management, teachers and learners to engaging in a collaborative approach to facilitate career education and future orientation at the school. There was reflection from management and LO teachers that a 'top-down' hierarchy exists in most schools and that needed to be shifted to accommodate learners' sense of future orientation as it had implications for their motivation and experiencing a sense of school membership. Learners' input on how the school could promote career education and motivation of learners emphasised the role of learners' voices in the school structure.

\section{Discussion}

Key findings of the evaluation results within an ecological framework indicated the efficacy of the interventions piloted to enhance motivation, future orientation and school membership. The outcome evaluation, using both the PSSM and FOS evidenced a strengthening of membership, motivation and future orientation. Themes from the qualitative process evaluation that gauged the voices of learners, teachers and school managers suggested the potential and possibilities for intervening at the interpersonal and school community level. The findings of this study, in a limited way, supports an approach to career education that encourages a programme of activities at the different levels that can systematically and collaboratively shift beyond the boundaries of academic subjects to 'enhance the career development of all students throughout the school experience' (Miller, in Peterson et al., 1991, p. 164).

Implications and recommendations for further research in the area highlight that the challenge for practitioners in scarce resource contexts is sensitising educators to the potential of whole-school programmes that integrate career education and engage with the relevant stakeholders. This is seen as particularly important for schools serving deprived areas and faced with limited career resources. As Mtolo (1996) indicates, ideally:

$[A]$ whole school approach and policy for career education must involve most teachers and all pupils, it must take into account of the problems of certain groups of people ... (especially) the disadvantaged economically. (p. 8) 
Mkhize and Akhurst (2006) indicated that this approach is dependent on teamwork from educators, and the highlighting of career education that proves integral to the different school subjects. They point out that career education should be the concern of every educator. However, in practice it is feared that owing to both educators' lack of training in this regard and their pressing concerns for their particular content areas, career education in South Africa will once again be neglected.

In reference to the responsibility of the school, the collaboration and the co-responsibility of various ecological stakeholders that include the parents of learners, managers and teachers, practitioners and service providers, cultural and community leaders and policymakers for young people's achievement of positive life outcomes (Masten, 2014; Ungar, 2013), is encouraged. With regard to the responsibility of psychologists (practitioners), this study draws attention to the training of practitioners for WSAs to career education and the importance of training psychologists for skills acquisition for both, establishing community-practitioner alliances in implementing intervention and evaluation, and monitoring of the intervention at multiple levels.

\section{Recommendations}

This study highlights the urgent need for career guidance in the school curriculum. Further studies on the effectiveness of multi-systemic interventions with a focus on career development are needed in South African schools. Such research needs to engage in the understanding of not only 'Which are the programmes and frameworks that work?', but 'Which combinations or sequences of strategies are most effective?', and 'How can schools be supported to effectively design comprehensive intervention prevention strategies and implement them in a high quality fashion?' In career development interventions, limited research has been conducted on the potential additive and multiplicative effect of the combinations of distinct programmes. Research is needed on the relative effectiveness of sets of interventions in order to develop a knowledge base to guide decisions about which combinations are most effective (Wilson, Gotfredson, \& Najaka, 2001). This is seen as most relevant in the South African education context, where great disparities in education are noted. South African provinces comprise different rural areas with schools that are markedly different from one another. Challenges are linked to socio-economic factors and limited infrastructure that impact the quality of the education. The Department of Education (2006) is cognizant that improving the schooling system must go beyond 'fixing up schools' and that greater work must be done to promote social cohesion and working together of role players involved in the school. The 'one size fit for all' approach to intervention that facilitates 'top-down' thinking also prevents effective whole-school development. The eco-systemic perspective that encourages participation and collaboration of all role players is thus highlighted in this research.
The role of parents and the involvement of the School Governing Body (SGB) in promoting WSAs are also referred to. The South African Schools Act (1996, p. 1) refers to the SGBs as a statutory structure and indicates that it is a compulsory requirement that every public school have such a governing body that represents the school community. The importance of research in exploring their role in promoting a sense of collaboration, cooperation and participation in WSAs to career education is highlighted.

\section{Limitations}

A limitation of this research is that it was a pilot study with the intervention only being implemented in one school. However, the conceptualisation and complexity of the research design evaluation, involving a quasi-experimental, pre- and post-measures and a control school, as opposed to a single experimental design, is however seen to have applicability of the findings to inform intervention work in the South African education context. Various researchers have also encouraged the reporting of such study findings. Van Teijlingen et al. (2001) indicated that pilot studies can inform us about the most effective process for researching phenomena, and can yield much information about the likely outcomes. Van Teijlingen et al. (2001) supported the reporting of pilot studies, especially when research in an area is limited and models and frameworks are needed to inform further work. Prescott and Soeken (1989) also indicated the 'underreporting' of pilot studies. Comprehensive reports of pilot studies are also found to be rare in research literature (Linquist, 1991; Van Teijlingen et al., 2001). Researchers, according to Van Teijlingen et al. (2001) are ethically obliged to draw from their research experience and report issues arising from all parts of a study, including the pilot phase.

\section{Conclusion}

Various studies in South Africa have emphasised the need of young people for career education. Chuenyane's (1983) study indicated $90 \%$ of the African high school population had 'serious career planning problems' (p. 278). This has also been identified by numerous studies in the last decade (Mtolo, 1996; Ntshngase, 1995) where learners have pleaded for career education in secondary schools. This study provides a framework that evidences it is possible to intervene at multiple levels within public South African secondary schools to inform adolescents' sense of future orientation, motivation and school membership. It highlights how future research could systematically enable and evaluate career development intervention at multiple levels, and the role this can play in potentially reducing adolescent engagement in high-risk behaviour. This study provides one such example that in promoting career education to benefit the future of adolescents, building community practitioner alliances through WSAs is possible and is in light of Maree (2020), a call for counsellors to innovate and contextualise their career counselling practice for relevance in scarce resource contexts. 


\section{Acknowledgements}

The author would like to acknowledge the study participants.

\section{Competing interests}

The author declares that she has no financial or personal relationships that may have inappropriately influenced her in writing this article.

\section{Author's contribution}

K.R. is the sole author of this research article.

\section{Funding information}

This research was conducted with the support of doctoral research grant received from the University of KwaZulu-Natal.

\section{Data availability}

The author confirms that the data supporting the findings of this study are available within the article.

\section{Disclaimer}

The views and opinions expressed in this article are those of the author and do not necessarily reflect the official policy or position of any affiliated agency of the author.

\section{References}

Akhurst, J., \& Mkhize, N.J. (2006). Career education in South Africa. In G.G. Stead \& M.B. Watson (Eds.), Career psychology in the South African context (2nd edn. pp. 139-153). Pretoria: Van Schaik.

Alm, S., Låftman Brolin, S., Sandahlc, J., \& Modinb, B. (2019). School effectiveness and students' future orientation: A multilevel analysis of upper secondary schools in Stockholm, Sweden. Journal of Adolescence, 70, 62-73. https://doi. org/10.1016/j.adolescence.2018.11.007

Avent, C. (1988). Careers across the curriculum. London: Macmillan.

Braddock, II, J.H., \& McPartland, J.M. (1993). Education of early adolescents. Review of Research in Education, 19(1), 3-49. https://doi.org/10.2307/1167342

Bronfenbrenner, U., (1979). The ecology of human development: Experiments by nature and design. Cambridge, MA: Harvard University Press.

Broomfield, K.A. (2007). Mechanisms through which supportive adult relationships and future orientation contribute to positive outcomes in low-income AfricanAmerican adolescents. Retrieved from https://scholarworks.gsu.edu/psych diss/33/

Campbell, D.T., \& Stanley, J.C. (1963). Experimental and quasi experimental designs for research. Chicago, IL: Rand McNally \& Company.

Chuenyane, Z.M. (1983). Career guidance needs assessment of black secondary school students in the Transvaal province of the Republic of South Africa. International Journal for the Advancement of Counselling, 6, 271-280. https://doi. org/10.1007/BF00118927

Department of Education (DOE). (2006). National framework for quality education in rural areas. Pretoria: Department of Education.

Department of Higher Education and Training (DHET). (2014). A competency framework for career development practitioners in South Africa. Retrieved from www.gpwonline.co.za

De Volder, M.L., \& Lens, W. (1982). Academic achievement and future time perspective as a cognitive-motivational concept. Journal of Personality and Social Psychology, 42(3), 566-571. https://doi.org/10.1037/0022-3514.42.3.566

Eccles, J.S., \& Midgley, C. (1989). Stage/environment fit: Developmentally appropriate classrooms for early adolescents. In C. Ames \& R. Ames (Eds.), Research on motivation in education (Vol. 3, pp. 139-186). New York: Academic Press.

Feather, N.T., \& Bond, M.J. (1983). Time structure and purposeful activity among employed and unemployed university graduates. Journal of Occupational Psychology, 56(3), 241-254. https://doi.org/10.1111/j.2044-8325.1983.tb00131.x
Fitzgerald, L.F., \& Betz, N.E. (1994). Career development in cultural context: The role of gender, race, class, and sexual orientation. In M. L. Savickas, \& R.W. Lent (Eds.), Convergence in career development theories: Implications for science and practice (pp. 103-117). Palo Alto, CA: CPP Books.

Fuligni, A.J. (1997). The academic achievement of adolescents from immigrant families: The roles of family background, attitudes and behaviour. Child Development, 68(2), 351-363. https://doi.org/10.1111/j.1467-8624.1997. Development,
tb01944.x

Gilbody, S., \& Whitty, P. (2002). Improving the delivery and organisation of mental health services: Beyond the conventional randomised controlled trial. British Journal of Psychiatry, 180(1), 13-18. https://doi.org/10.1192/bjp.180.1.13

Goodenow, C. (1993). The psychological sense of school membership among adolescents: Scale development and educational correlates. Psychology in the Schools, 30(1), 79-90. https://doi.org/10.1002/1520-6807(199301)30:1\%3C79:: AID-PITS2310300113\%3E3.0.CO;2-X

Gounden, Y. (2009). Navigational tools in career guidance: Constructing work and study paths. SAQA Update, 11(2\&3), 6-7.

Hardré, P.L., Crowson, H.M., Debacker, T.K., \& White, D., (2007). Predicting the academic motivation of rural high school students. The Journal of Experimental Education 75(4), 247-269.

Ibanez, G.E., Kuperminc, G.P., Jurkovic, G., \& Perilla, J. (2004). Cultural attributes and adaptations linked to achievement and motivation among Latino adolescents. Journal of Youth and Adolescence, 33, 559-568.

Kerpelman, J.L., \& Mosher, L.S. (2004). Rural African American adolescents future orientation: The importance of self-efficacy, control and responsibility, and identity development. Identity: An International Journal of Theory and Research, 4(2), 187-208. https://doi.org/10.1207/s1532706xid0402_5

Kezar, A. (2002). Reconstructing static images of leadership: An application of positionality theory. Journal of Leadership Studies, 8(3), 94-109. https://doi. org/10.1177/107179190200800308

Lindquist, R. (1991). Don't forget the pilot work! Heart Lung, 20, 91-92.

Maree, J.G. (2013). Latest developments in career counselling in South Africa: towards a positive approach. South African Journal of Psychology, 43(4), 409-421.

Maree, J.G. (2020). Innovating counseling for self- and career construction: Connecting conscious knowledge with subconscious insight. New York, NY: Springer.

Marko, K.W., \& Savickas, M.L. (1998). Effectiveness of a career theme perspective intervention. Journal of Vocational Behaviour, 52, 106-119.

Masten, A.S. (2014). Ordinary magic: Resilience in development. New York, NY: Guilford Press.

Miles, J. (2015). The impact of a career development programme on the career self-efficacy and academic motivation of Grade 11 learners from diverse socio-economic backgrounds. Unpublished doctoral dissertation. Cape Town Stellenbosch University.

Mtolo, M.Z. (1996). Tertiary students' perspectives on secondary school career education: A consumer perspective. Unpublished master's dissertation. Pietermaritzburg: University of Natal.

Ntshngase, S.M. (1995). A study of black high school pupils' perceptions of the usefulness of school counsellors. Unpublished master's dissertation. Pietermaritzberg: University of Natal.

Nurmi, J.E. (1991). How do adolescents see their future? A review of the development of future orientation and planning. Developmental Review, 11(1) 1-59. https://doi.org/10.1016/0273-2297(91)90002-6

Nurmi, J.E., \& Salmelo-Aro, K. (2002). Goal construction, reconstruction and depressive symptomatology in a life span context: The transition from school to work. Journal of Personality, 70(3), 385-420. https://doi.org/10.1111/1467work. Journ

Peterson, G.W., Sampson, J.P., \& Reardon, R.C. (1991). Career development and services: A cognitive approach. Pacific Grove, CA: Brooks Cole.

Rawatlal, K.V. (2014). The development, implementation and evaluation of interventions to build school connectedness: A pilot study. Unpublished doctoral dissertation, South Africa: University of KwaZulu-Natal.

Rawatlal, K.V., \& Petersen, I. (2012). Factors impeding school connectedness: A case-study. South African Journal of Psychology, 42(3), 346-357. https://doi. org/10.1177/008124631204200306

Republic of South Africa. (1996). Government Gazette No. 19347. 12/10/1998 South African Schools Act. General notice 2362. Pretoria: Government Publishers.

Resnick, M.D., Bearman, P.S., Blum, R.W., Bauman, K.E., Harris, K.M., Jones, J. et al., (1997). Protecting adolescents from harm: Findings from the national longitudinal study on adolescent health. Journal of the American Medical Association, 278(10), 823-832. https://doi.org/10.1001/jama.1997. 03550100049038

Richie, J., \& Spencer, L. (1994). Qualitative data analysis for applied policy research. In A. Bryman \& B. Burgess (Eds.), Analysing qualitative data (pp. 174-194). London: Routledge.

Savickas, M.L. (2012a). Life design: A paradigm for career intervention in the 21st century. Journal of Counseling \& Development, 90(1), 13-19. https://doi. org/10.1111/j.1556-6676.2012.00002.x

Savickas, M.L. (2012b). Toward a taxonomy of human strengths: Career. In W.B. Walsh (Ed.), Counseling psychology and optimal human functioning (3rd edn., pp. 229-250). New York, NY: Routledge. 
Singh, J. (2003). The perception and experiences of educators on the implementation of whole school development in a disadvantaged school: Guidelines for the Educational Psychologist. Unpublished master's dissertation. Gauteng: Rand
Afrikaans University.

Stead, G.B., \& Watson, M.B. (2006). Career education in South Africa. In G.B. Stead \& M.B. Watson (Eds.), Career psychology in the South African context (2nd edn., pp. 139-153). Pretoria: Van Schaik.

Ungar, M. (2013). Resilience, trauma, context, and culture. Trauma, Violence, \& Abuse, 14(3), 255-266. https://doi.org/10.1177/1524838013487805

Van Teijlingen, E.R., Rennie, A.M., Hundley, V., \& Graham, W. (2001). The importance of conducting and reporting pilot studies: The example of the Scottish birth survey. Journal of Advanced Nursing, 34(3), 289-295. https://doi.org/10.1046/ j.1365-2648.2001.01757.x
Watson, M. (2010). Career psychology in South Africa: Addressing and redressing social justice. Australian Journal of Career Development, 19(1), 24-29. https:// doi.org/10.1177/103841621001900106

Watts, A.G. (2009). The role of career guidance in the development of the national qualifications framework in South Africa. In South African Qualifications Authority, career guidance challenges and opportunities (pp. 6-12). Waterkloof, South Africa: South African Qualifications Authority.

Weare, K., \& Markham, W. (2005). What we know about promoting mental health through schools? Promotion and education, 12(3-4), 118-22. https:// doi.org/10.1177/10253823050120030104

Wilson, D.B., Gotfredson, D.C., \& Najaka, S.S., (2001). School-based prevention of problem behaviours: A meta-analysis. Journal of Quantitative Criminology, 17 247-272. https://doi.org/10.1023/A:1011050217296 